\title{
Reciclar é educar: a importância do Programa de Educação Ambiental (PEAM) para a Universidade Regional do Cariri (URCA) em Crato - CE
}

Recycling is educating: the importance of the Environmental Education Program (PEAM) for the Regional University of Cariri (URCA) in Crato - CE

Reciclar es educar: la importancia del Programa de Educación Ambiental (PEAM) para la Universidad Regional de Cariri (URCA) en Crato - CE

Ginna Gonçalves Pereira ORCID: https://orcid.org/0000-0003-0267-2615 Universidade Regional do Cariri, Brasil

E-mail:ginna.pereira@urca.br

Dennis Bezerra Correia

ORCID: https://orcid.org/0000-0002-7782-4767 Universidade Regional do Cariri, Brasil

E-mail: denniscorreia40@gmail.com

Bruno Melo de Alcântara

ORCID: https://orcid.org/0000-0002-1996-2424 Universidade Regional do Cariri, Brasil

E-mail: brunomelo870@gmail.com

Rafael Henrique Luciano dos Santos

ORCID: https://orcid.org/0000-0001-6968-6803 Secretaria de Educação e Esportes de Pernambuco, Brasil E-mail: rafaelhenrique.bio@gmail.com

Jamile Maria Pereira Bastos Lira de Vasconcelos

ORCID: https://orcid.org/0000-0002-0898-0643 Secretaria de Educação e Esportes de Pernambuco, Brasil E-mail: jamilebastoslira@gmail.com

Cícero Jorge Verçosa ORCID: https://orcid.org/0000-0002-3284-6719 Secretaria de Educação e Esportes de Pernambuco, Brasil

E-mail: cjvercosa@hotmail.com

João Paulo Camilo de Oliveira ORCID: https://orcid.org/0000-0003-0286-1149 Universidade Regional do Cariri, Brasil

E-mail: camilodeoliveirajoaopaulo35@gmail.com

Elias Laurindo de Oliveira

ORCID: https://orcid.org/0000-0002-2456-8296 Universidade Regional do Cariri, Brasil E-mail: eliasescarpa@gmail.com

Thiago Felix de Lima

ORCID: https://orcid.org/0000-0001-8577-4635 Universidade Federal do Cariri, Brasil E-mail: lima.thiago@aluno.ufca.edu.br

Bruna Almeida de Oliveira ORCID: https://orcid.org/0000-0003-3937-8038 Universidade Estadual Vale do Acaraú, Brasil E-mail: brunalmeidaprof@gmail.com

Joana Dalvanira Ferreira

ORCID: https://orcid.org/0000-0002-4350-7165 Universidade Regional do Cariri, Brasil E-mail: dfjoana@gmail.com

Antônio Carlito Bezerra dos Santos ORCID: https://orcid.org/0000-0002-2095-5512 Universidade Regional do Cariri, Brasil E-mail: carlito.santos@urca.br

\section{Resumo}

Com o presente trabalho objetivou-se apresentar a importância do Programa de Educação Ambiental (PEAM) que está sendo desenvolvido na Universidade Regional do Cariri - URCA, campus Pimenta, no município de Crato-CE, bem 
como, reconhecer o mesmo como uma estratégia pedagógica para uma melhor gestão dos resíduos sólidos. O programa conta com parcerias de algumas empresas, constando de várias etapas e campanhas, como a divulgação nos setores administrativos e acadêmicos da universidade, coleta de papel reciclável nos departamentos, campanha de minimização do consumo de água e energia na instituição, campanha de coleta de óleo de cozinha e palestras de Educação Ambiental em escolas municipais. Até o presente momento já foram recolhidos $2.044 \mathrm{Kg}$ de resíduos sólidos, sendo a maior parte composta de papel, oriundos dos setores administrativos e acadêmicos da universidade e recebidos aproximadamente 300 litros de óleo, o qual foi encaminhado à empresa Sabão Juá. Foram produzidos 1200 adesivos, que foram afixados em diferentes setores e áreas do campus da URCA, no intuito de contribuir para o racionamento de água e energia. Foram realizadas palestras em quatro escolas como forma de divulgar o referido programa. Os resultados observados sugerem uma efetiva mudança no comportamento da comunidade acadêmica da URCA no que diz respeito à separação de resíduos para reciclagem, considerando o entendimento de que coibir a degradação ambiental entre outras não é só dever do gestor ambiental, mas de todos quanto, cidadãos empenhados em projetar as consequências e avaliar alternativas para mitigar os impactos provocados pela atual geração de resíduos no ambiente.

Palavras-chave: Crise ambiental; Conscientização; Resíduos sólidos; Coleta.

\begin{abstract}
The present work aimed to present the importance of the Environmental Education Program (PEAM) that is being developed at the Regional University of Cariri - URCA, Pimenta campus, in the municipality of Crato-CE, as well as to recognize it as a pedagogical strategy for better management of solid waste. The program has partnerships with some companies, consisting of several stages and campaigns, such as publicity in the administrative and academic sectors of the university, collection of recyclable paper in departments, campaign to minimize water and energy consumption in the institution, campaign to collect cooking oil and lectures on Environmental Education in municipal schools. So far, $2,044 \mathrm{~kg}$ of solid waste have been collected, most of which is made up of paper, coming from the university's administrative and academic sectors. Approximately 300 liters of oil were received, which was sent to the company Sabão Juá. 1200 stickers were produced, which were posted in different sectors and areas of the URCA campus, in order to contribute to the rationing of water and energy. Lectures were held in four schools as a way to publicize the program. The observed results suggest an effective change in the behavior of the academic community of URCA with regard to the separation of waste for recycling, considering the understanding that curbing environmental degradation, among others, is not only the duty of the environmental manager, but of all, citizens. committed to projecting the consequences and evaluating alternatives to mitigate the impacts caused by the current generation of waste on the environment.
\end{abstract}

Keywords: Environmental crisis; Conscientization; Solid waste; Pigtail.

\title{
Resumen
}

El presente trabajo tuvo como objetivo presentar la importancia del Programa de Educación Ambiental (PEAM) que se viene desarrollando en la Universidad Regional del Cariri - URCA, campus Pimenta, en el municipio de Crato-CE, así como reconocerlo como estrategia pedagógica. para una mejor gestión de los residuos sólidos. El programa tiene alianzas con algunas empresas, consta de varias etapas y campañas, como difusión en los sectores administrativos y académicos de la universidad, recolección de papel reciclable en los departamentos, campaña para minimizar el consumo de agua y energía en la institución, campaña de recolección para cocinar aceite y charlas sobre Educación Ambiental en escuelas municipales. Hasta el momento, fueron recolectados $2.044 \mathrm{~kg}$ de residuos sólidos, la mayor parte de papel, provenientes de los sectores administrativos y académicos de la universidad y fueron recibidos aproximadamente 300 litros de aceite, que fue enviado a la empresa Sabão Juá. Se elaboraron 1200 stickers, que fueron pegados en diferentes sectores y áreas del campus de la URCA, con el fin de contribuir al racionamiento de agua y energía. Se realizaron charlas en cuatro escuelas como una forma de dar a conocer el programa. Los resultados observados sugieren un cambio efectivo en el comportamiento de la comunidad académica de la URCA con respecto a la separación de residuos para el reciclaje, considerando el entendimiento de que frenar la degradación ambiental, entre otros, es deber no sólo del gestor ambiental, sino de todos, ciudadanos comprometidos con proyectar las consecuencias y evaluar alternativas para mitigar los impactos que genera la actual generación de residuos en el medio ambiente.

Palabras clave: Crise ambiental; Concienciación; Resíduos sólidos; Coleta.

\section{Introdução}

Um dos grandes problemas no acúmulo de lixo nos centros urbanos é o pouco ou nenhum conhecimento do que realmente significa lixo e o que são resíduos sólidos. "A palavra lixo vem do latim lix que significa cinzas, que tem relação com os restos de carvão provenientes dos fogões" (Mucelin \& Bellini, 2008). Todavia, nas últimas décadas, esta definição foi 
tornando-se algo que era obsoleto, em algo que possa ser reutilizado e o que antes era lixo passou a ser chamado resíduo sólido. A palavra resíduo vem do latim residuum que significa "sobra, resto". Assim, podemos destacar que lixo é tudo aquilo que não tem mais valor e resíduo, por outro lado, é o que ainda pode ser reutilizado, reciclado e transformado pelo homem, afim de minimizar a exploração dos recursos naturais.

Diante do exposto, pode-se salientar que a ausência de políticas públicas eficientes e a desorientação em torno de rejeito/resíduo, pode, muitas vezes, causar problemas, como o seu aglomerado nos centros urbanos que, por sua vez, está atrelado à cultura de consumo da população. Para Pereira, Oliveira e Vieira (2013), quanto mais se consome, mais os veículos de comunicação tendem a impulsionar o ritmo de aquisição de novos produtos. E o problema está justamente no consumo excessivo inconsciente, pois, quanto mais se consome, de forma irresponsável, mais se produz lixo.

De acordo com Costa, Lopes e Lopes (2015), o lixo tornou-se um dos problemas preocupantes nos dias de hoje, isto porque os recursos naturais da Terra estão se esvaindo e não há mais o que fazer com tanto "lixo". Para Araújo e Costa (2003), retirar os resíduos dos ambientes onde ele se acumula exige tempo, energia e espaço e, consequentemente, muito dinheiro. Desta forma, o aglomerado crescente de resíduos nos centros urbanos influencia diretamente na economia local, uma vez que quanto mais lixo, maior a necessidade de coleta e locais adequados para o deposito do mesmo. Essa crise ambiental esta associada a maior atividade antrópica e menor percepção dos impactos associados a produção de resíduos sólidos (Almeida et al., 2021).

O que se deve considerar são medidas que possam reduzir o lixo/resíduos das cidades, tendo como primeiro passo uma visão voltada à sustentabilidade que vem com a Educação Ambiental da população e a implantação da coleta seletiva eficiente. Para Almeida e Silva (2021), o desenvolvimento sustentável está atrelado a produção de novos produtos a partir de resíduos sólidos urbanos, tendo como resultado a produção de insumos produtivos.

Mediante aos problemas apresentados, torna-se necessário, portanto, estabelecer um vínculo entre educação e ambiente. É nesse contexto que se inserem as práticas da Educação Ambiental como forma de amenizar os problemas que o descarte inadequado de materiais pode acarretar. Atividades que vissem a sensibilização e conscientização da população tem como objetivo colocar em prática a utilização de recursos naturais de forma adequada (Silva et al., 2014).

Neste contexto, com o presente trabalho objetivou-se apresentar a importância do Programa de Educação Ambiental (PEAM) que está sendo desenvolvido na Universidade Regional do Cariri - URCA, campus Pimenta, no município de Crato$\mathrm{CE}$, bem como, reconhece-lo como uma estratégia pedagógica para uma melhor gestão dos resíduos sólidos, inserindo práticas de Educação Ambiental junto ao corpo docente, discentes e funcionários da instituição.

\section{Metodologia}

\section{1 Área de estudo}

O trabalho foi desenvolvido no Programa de Educação Ambiental vinculado a Pró-reitora de Extensão (PROEX) da Universidade Regional do Cariri (URCA), campus Pimenta, no município de Crato-CE no período de março de 2016 a dezembro de 2017.

\subsection{Etapas do Programa:}

\subsubsection{Parcerias}

A princípio, foi firmada uma parceria com o grupo Farmace, empresa que desenvolve, produz, comercializa e distribui medicamentos e suplementos alimentares. A empresa fica situada no município de Barbalha-CE há 20Km da cidade do CratoCE. 
A referida empresa cedeu, inicialmente, 70 barricas de papelão, com capacidade para $50 \mathrm{Kg}$ que eram utilizados anteriormente para distribuição de ampolas de medicamentos (Figura 1a). Após a entrega dos fármacos, as barricas eram inutilizáveis, sendo descartadas em locais inapropriados. Diante disso, os toneis foram doados ao programa e transformados em coletores para papel reciclável, sendo personalizados com a logomarca do programa (Figura 1b).

Figura 1: Barricas de papelão cedidas pela empresa Farmace. Legenda: (A) Barricas vazias que eram utilizadas na distribuição de ampolas de medicamentos. (B) Coletor adesivado para o recolhimento de papel para reciclagem no Programa de Educação Ambiental da URCA.
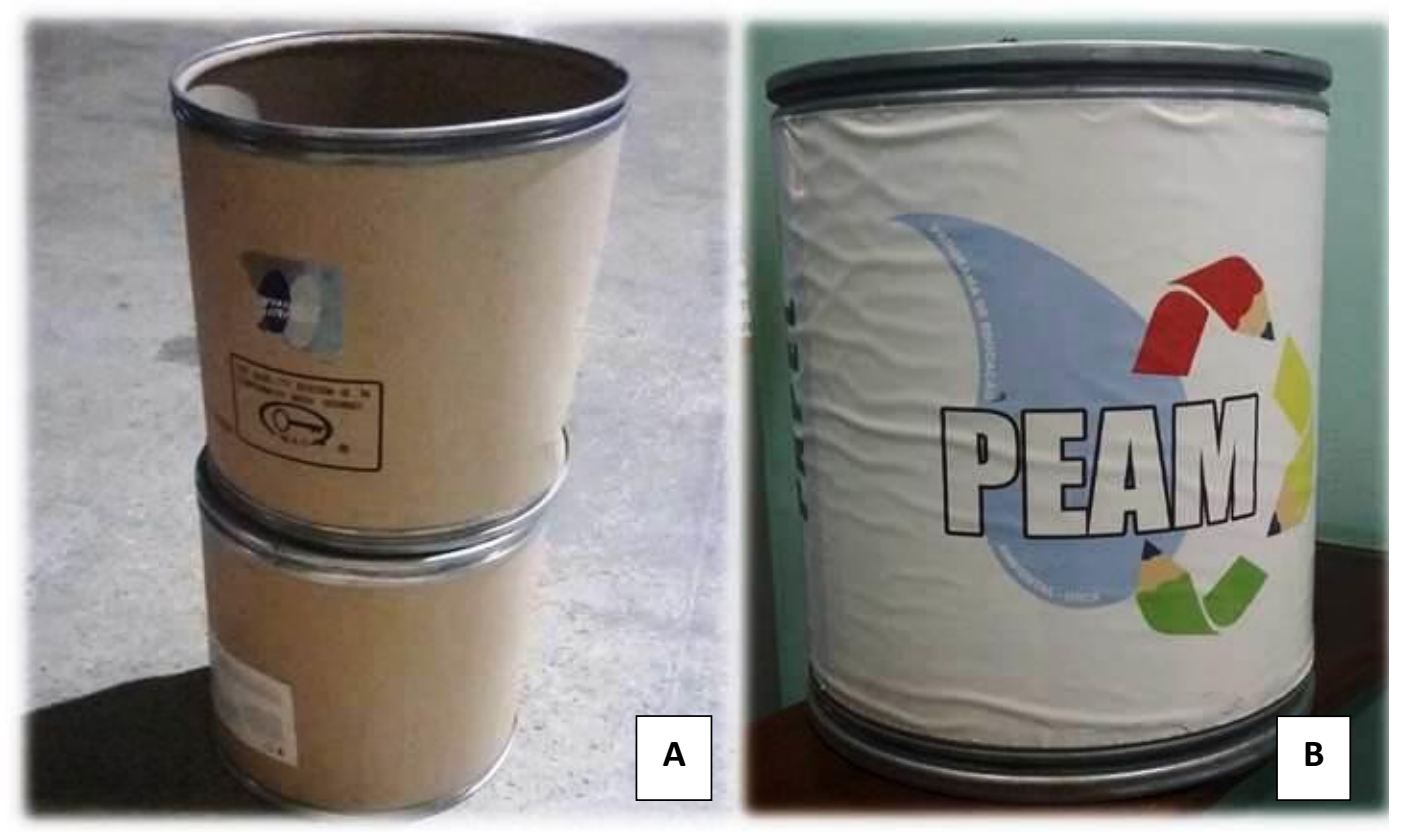

Fonte: Autores.

Posteriormente, foi estabelecida uma parceria com a Associação dos Agentes Recicladores do Crato-CE (AARC) para o recolhido semanal dos resíduos produzidos e recebidos na Universidade.

A associação foi fundada no ano de 2005, onde atualmente participam mais de 15 famílias que anteriormente trabalhavam em lixões. A associação tem sede no bairro Recreio no município de Crato - CE.

O Programa de Educação Ambiental, também contou com a parceria da Tetra Pak, empresa multinacional de processamento e envase de alimentos, com embalagens sustentáveis, tendo sede na Suécia. No Brasil, a empresa desenvolve um projeto de implantar ecopontos em escolas e universidades para coleta de diversos materiais que possam ser reciclados. Assim, através do Programa de Educação Ambiental (PEAM) da URCA, a referida empresa, instalou na universidade um ecoponto (Figura 2), para que o programa pudesse trabalhar com os demais materiais recicláveis. 
Figura 2: Ecoponto instalado na Universidade Regional do Cariri - URCA para o recolhimento dos materiais recicláveis.

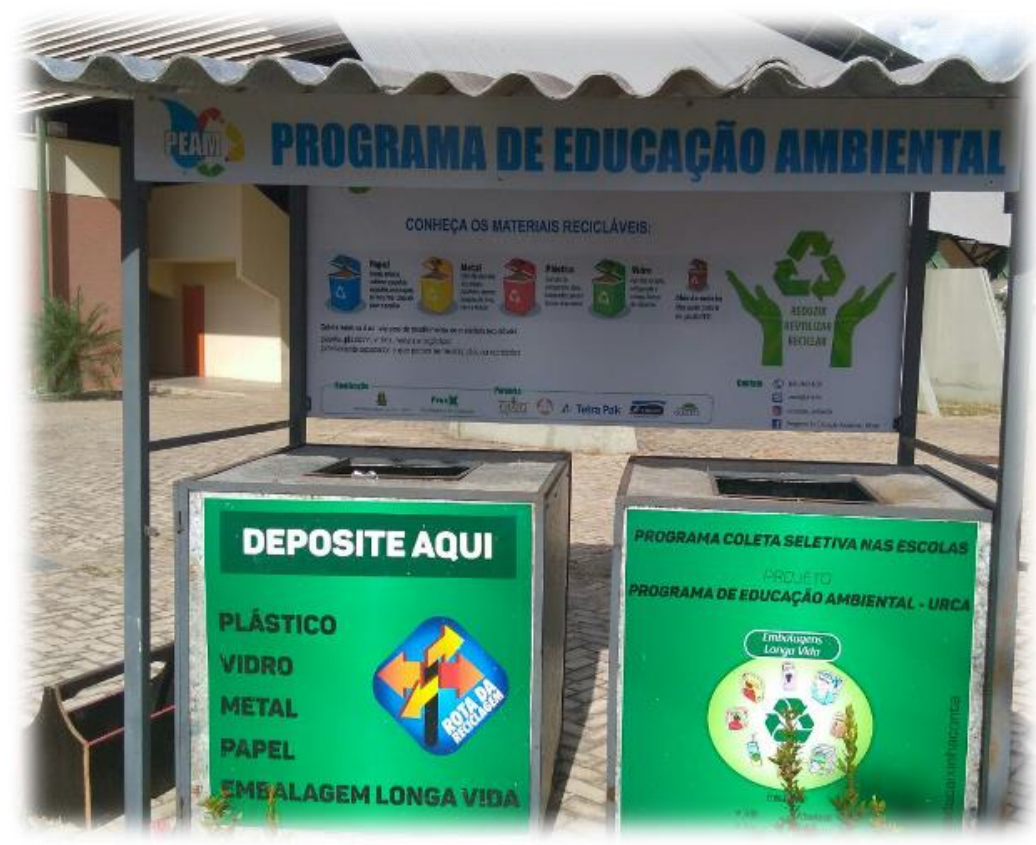

Fonte: Autores.

Posteriormente foi feita uma parceria entre o programa PEAM e a empresa Sabão Juá, esta com sede no município de Juazeiro do Norte-CE, há $14 \mathrm{Km}$ da cidade de Crato-CE. A empresa desenvolve campanhas de arrecadação de óleo de cozinha já utilizado para fabricação de sabão, onde parte da renda obtida é revertida em doação para o Instituto de Apoio à Crianças com Câncer (IACC). Com a parceria, a entidade forneceu coletores com capacidade de 25L para que o óleo fosse arrecadado na universidade e transportado para a sede da empresa (Figura 3).

Figura 3: Coletor para o recolhimento de óleo de cozinha doado pela Empresa Sabão Juá ao Programa de Educação Ambiental na URCA.

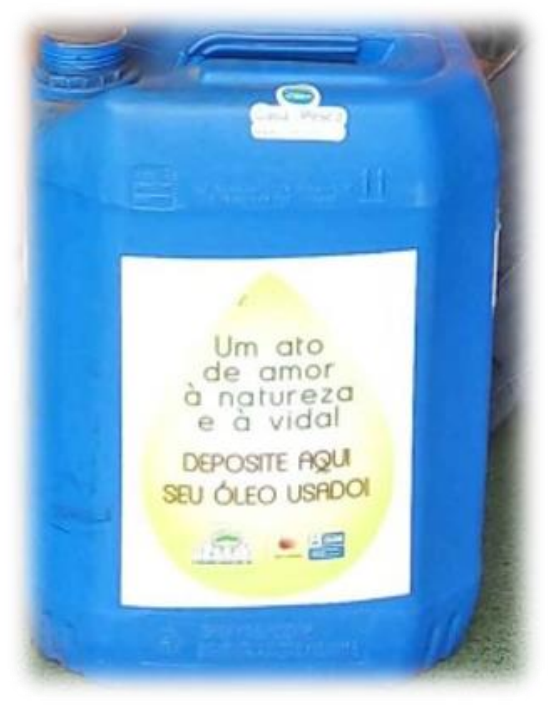

Fonte: Autores. 


\subsubsection{Divulgação do programa e monitoramento dos coletores junto aos setores administrativos e acadêmicos da URCA}

Primeiramente, houve uma reunião com Pró-reitores, Chefes e Coordenadores de cada setor para que o programa e seus objetivos fossem expostos, bem como, oferecer orientação de como deveria ser feito o descarte de papel no coletor. Na oportunidade, foram adesivados 40 coletores para serem entregues nos principais setores da instituição.

Após os coletores serem entregues aos setores, os bolsistas se responsabilizariam por acompanhar semanalmente o controle de coleta, a fim de verificar a necessidade de recolhimento. Dessa forma, foi criada uma tabela com o nome de cada setor que recebeu o coletor, bem como, a data do monitoramento e o registrado da situação em que o coletor se encontrava cheio ou vazio (Anexo1).

No monitoramento, o coletor que se encontrava cheio era realizada a coleta e o material encaminhado ao ecoponto para o seu recolhido pela associação.

\subsubsection{Capacitação com os funcionários da limpeza da URCA}

Os materiais depositados nos coletores teriam destino diferente dos demais materiais dos coletores comuns. Com isso, foi imprescindível um preparo inicial dos funcionários da limpeza da instituição.

Neste momento, foi exposto, inicialmente os impactos que o acúmulo de lixo traz ao ambiente, à economia e principalmente à saúde pública. Em seguida, foi apresentado a importância da coleta seletiva, bem como, quais os materiais que podem ou não serem reciclados, para que haja a minimização desses impactos. Posteriormente, foram apresentando os objetivos e como o programa seria desenvolvido, deixando claro a importância da colaboração de cada um para o sucesso do PEAM.

Na ocasião, também se fez necessário uma capacitação quanto à importância do uso de EPI's - Equipamentos de Proteção Individual, visto que, foi constatado o mau uso ou total desuso destes pelos funcionários, mesmo a universidade tendo disponibilizado essa proteção. Desta forma, foram apresentados os principais riscos que o desuso dos EPI's pode trazer à saúde das pessoas que trabalham diretamente com o lixo e materiais utilizados em limpeza de ambientes.

\subsubsection{Divulgação do programa junto à comunidade acadêmica}

Para a divulgação do programa junto aos discentes e docentes da universidade foram impressos dois banners 90x120cm, contendo informações gerais sobre o descarte incorreto de resíduos, coleta seletiva e objetivos gerais do programa (Figura 4). Na oportunidade, foi apresentado um coletor adesivado para informar como seria feita a coleta de papel reciclável nos departamentos.

Foram visitadas todas as salas de aulas dos cursos de graduação da Universidade Regional do Cariri - URCA, campus Pimenta. As visitas foram feitas com a colaboração dos professores, abrindo espaço no horário de suas aulas para que a divulgação acontecesse. A exposição contou com um breve resumo sobre a situação atual em que o meio ambiente se encontra em razão do descarte incorreto dos resíduos sólidos, assim como, mostrando como a coleta seletiva pode ser uma ferramenta essencial como resposta à crise ambiental atual. 
Figura 4: Modelo do banner utilizado para divulgação do Programa de Educação Ambiental - PEAM à comunidade acadêmica.

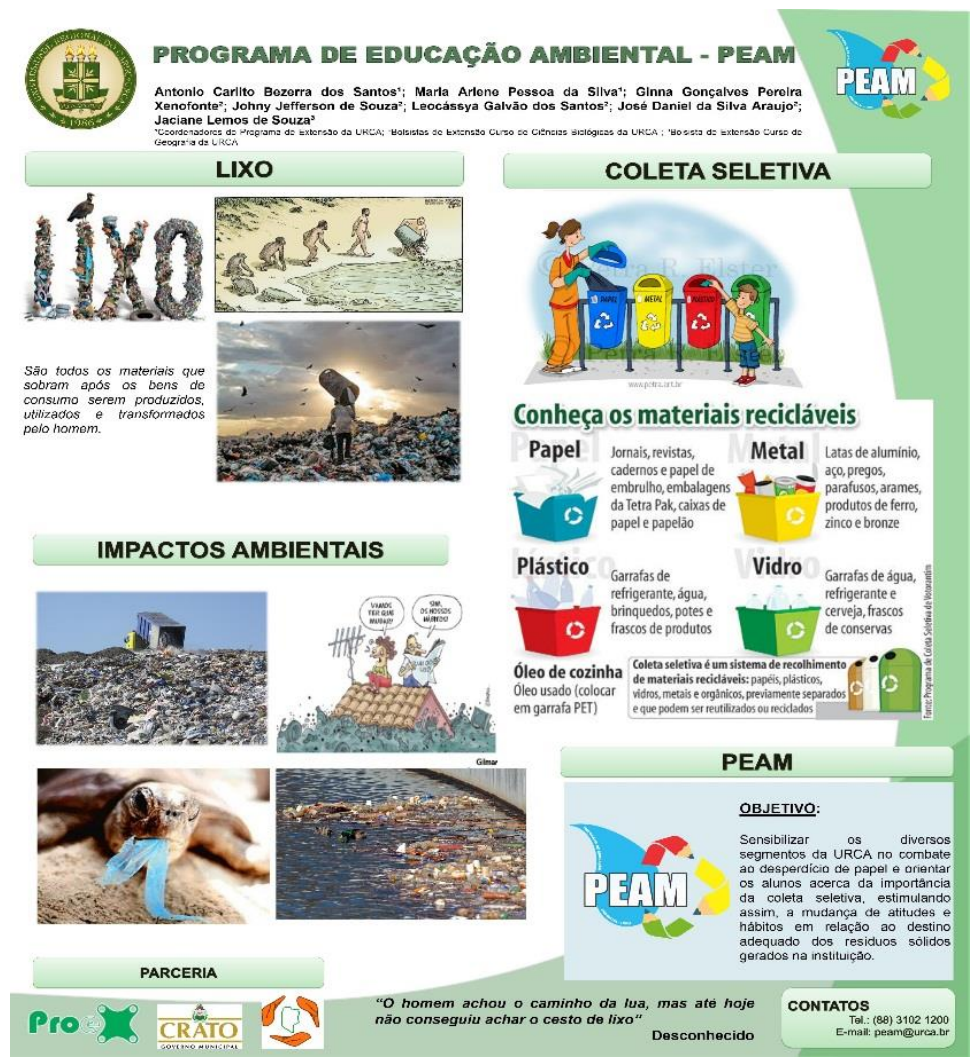

Fonte: Autores.

A exposição do programa aos discentes foi apresentada como um instrumento que tem o objetivo de modificar os hábitos de descarte incorreto dos resíduos na universidade, assim como, com o intuito de diminuir o acúmulo dos mesmos em ambientes inapropriados. Na oportunidade, foi enfatizado que o programa contaria com a participação de toda comunidade acadêmica (docentes, discentes e funcionários) para que possamos realizar suas atividades de modo efetivo.

\subsubsection{Campanha de divulgação da coleta do óleo de cozinha usado}

A campanha de coleta do óleo de cozinha já utilizado, assim como a divulgação do Programa, foi feita em todas as salas dos cursos de graduação da universidade, em horários de aulas matutino, vespertino e noturno. Para a campanha, foram feitos cartazes para expor em salas de aulas, bem como, doação garrafas pets adesivadas para o acondicionamento do óleo (Figura 5). 
Figura 5: Material de divulgação da campanha de óleo de cozinha usado. (A) Cartaz da campanha de coleta do óleo de cozinha utilizado. Legenda: (B) Garrafas pets etiquetadas para doação.

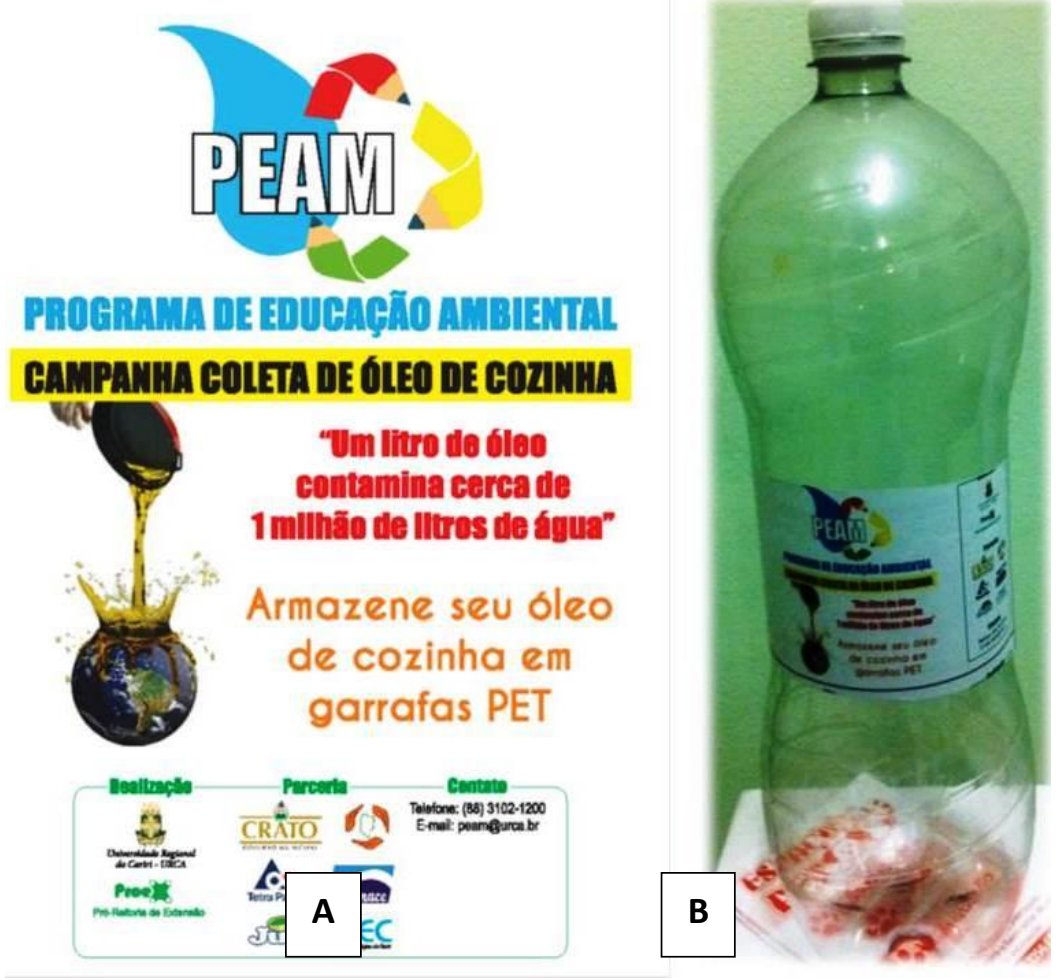

Fonte: Autores

No cartaz, foi indicado que a ação fazia parte do PEAM, assim como, informações sobre o problema ambiental do descarte incorreto de óleo de cozinha.

Durante as visitas em sala de aula, foram dadas informações gerais sobre as consequências que o descarte inapropriado da substância traria para encanamentos, tubulações e principalmente ao meio ambiente, poluindo a água potável e destruindo ecossistemas aquáticos. Na ocasião, foi dado conhecimento a respeito da campanha realizada pelo Sabão Juá e informado que o óleo coletado na instituição seguiria o mesmo destino.

Sucessivamente, foram entregues as garrafas pets adesivadas para os alunos e docentes presentes em sala que se interessaram em contribuir com a ação, sendo listados os nomes e os contatos. Incialmente foi indicado como ponto de entrega do material a Pró-reitora de Extensão (PROEX) da universidade, onde se encontravam os coletores disponibilizados pela empresa Sabão Juá.

\subsubsection{Campanha de redução do consumo de água e energia}

É evidente, na instituição, o desperdício de água e energia em diversos setores, como salas de aula, banheiros e departamentos. Logo, a campanha de redução de água e energia mostrou-se como uma forma de minimizar esse desperdício exacerbado.

Foram confeccionados 1200 adesivos informativos, sendo 300 para o consumo consciente de luz; 600 para o racionamento de água, tanto nas descargas quanto nas torneiras e 300 para o desligamento dos eletroeletrônicos (ventiladores, projetores, computadores, impressoras e geláguas). 
Os adesivos "Apague as luzes ao sair", foram fixados nos interruptores de todas as salas de aula; já os adesivos "Me poupe!", foram colocados próximos a descarga dos banheiros dos campus pimenta e residência universitária; enquanto os adesivos com informativos "Feche as torneiras após o uso", foram destinados além dos banheiros, aos laboratórios e ao restaurante universitário. Por fim, os adesivos informando que "Reduzir o consumo é transformar o mundo", foram fixados em todos os setores administrativos no intuito de não deixar os eletroeletrônicos ligados sem necessidade.

\subsubsection{Palestras e divulgação do programa nas escolas}

Esta etapa foi realizada com a exposição do PEAM, assim como, apresentação de palestras sobre a importância da Educação Ambiental no âmbito escolar e social; resíduos sólidos e impactos gerados pelo descarte incorreto de resíduos.

Até dezembro de 2017, quatro escolas foram agraciadas, que são: Escola de Ensino Fundamental Professor Natanael Cortez, localizada na Rua José Marrocos, Pinto Madeira, Crato-CE; Escola de Educação Infantil e Ensino Fundamental Professora Edilma Fernandes Galvão Rodrigues (Ciclo Operário), localizada no centro do Crato; Escola de Ensino Médio Colégio Estadual Wilson Gonçalves, localizada na Praça Joaquim Fernandes Teles, bairro Pimenta, Crato-CE e o Instituto Educacional Ciranda do Saber, escola de ensino privado, localizada no bairro seminário, no referido município.

As palestras contaram com uma série de problemáticas em torno da Educação Ambiental. Primeiramente, foi exibido um vídeo que tem por título "Ilha das Flores" que expõe questões ambientais relacionadas a problemas sociais, onde foram discutidos e pôde-se aplicar uma dinâmica onde foi possível observar os conhecimentos dos alunos sobre lixo e resíduo sólido. Subsequente, houve uma discussão sobre os impactos ambientais e de saúde pública gerados pelo descarte incorreto dos resíduos sólidos, bem como, os prejuízos econômicos e o que nós, como cidadãos, podemos fazer para minimizar esses problemas. Da mesma forma, a importância do descarte e coleta seletiva foram apresentados como soluções básicas e eficientes. Foram mostrados a diferença entre lixões, aterros controlados e aterros sanitários. Posteriormente, foi relatado como o PEAM surgiu e funciona na universidade, assim como, a campanha de arrecadação de óleo de cozinha que é feita em conjunto com o programa.

\section{Resultados e Discussão}

O Público beneficiado pelas ações educativas do GeoPark Araripe são escolas públicas e privadas, existe metas que só serão alcançadas a médio e longo prazos, o GeoPark Araripe busca trabalhar na realização de ações urgentes e nos projetos que existe tempo diferenciado para começar a mostrar resultados.

\subsection{Divulgação como forma de mobilização}

O programa foi divulgado aos 10 cursos de graduação da universidade, sendo visitadas 136 salas de aulas, 23 departamentos, oito Pró-reitorias e seis Centros. A divulgação alcançou cerca de cinco mil pessoas entre alunos e funcionários da universidade.

É de grande relevância, destacar, o valor que a informação possui. Para Barreto (1994), a informação sintoniza o mundo. Como onda ou partícula, participa na evolução e da revolução do homem em direção à sua história. Como elemento organizador, a informação referência o homem ao seu destino. Neste sentido, a instrução entra como ferramenta para que haja uma conscientização coletiva, propiciando assim, uma mobilização pública.

A instrução torna o cidadão consciente de sua realidade socioambiental, mediante a obtenção de vários tipos de conhecimento sobre ela (Zitzke, 2002). Dessa maneira, a divulgação do PEAM para os funcionários, discentes e docentes, apresentou-se de modo eficiente no que diz respeito à disseminação da informação, bem como, mostrou-se de caráter 
mobilizador, pois da mesma forma, teve natureza sensibilizadora no que diz respeito a trazer uma nova visão sobre o modo pelo qual agimos sobre o meio ambiente.

\subsection{Capacitação como uma perspectiva transformadora para os funcionários da limpeza da URCA}

Até dezembro de 2017 foram capacitados 30\% dos funcionários da universidade. É imprescindível afirmar que o conhecimento, além de mudança de hábitos, leva o entendimento sobre certos valores. Felix (2007) afirmou que o processo educacional, faz com que as pessoas se apropriem dos conhecimentos fornecidos e seja capaz de agir de forma responsável diante do ambiente em que vive. Assim, podemos tomar a capacitação fornecida aos funcionários da limpeza, como um processo educacional, ainda que essas pessoas tenham obtido acesso à educação, esta, deve ser continuada, para o aperfeiçoamento, ou seja, ainda que eles soubessem a definição de coleta seletiva, a capacitação trouxe seu real valor, além de defini-la como ferramenta essencial para a transformação da realidade ambiental, bem como, torna-los indispensáveis para a realização dessas práticas.

Além da importância da temática sobre coleta seletiva, o assunto acerca do uso dos EPI's foi fundamental para que eles tivessem uma percepção mais satisfatória sobre acidentes de trabalho e doenças ocupacionais, visto que o uso desses equipamentos era dispensado pelos profissionais.

Segundo Cisz (2015), os acidentes de trabalho são os maiores desafios para a saúde do trabalhador, atualmente e no futuro. De acordo com a Organização Panamericana de Saúde (Opas, 2006), estes desafios estão ligados aos problemas de saúde ocupacional, com as novas tecnologias, novas substâncias químicas, problemas relacionados com a crescente mobilidade dos trabalhadores e ocorrência de novas doenças ocupacionais.

Dessa forma, o curto treinamento sobre o uso de equipamentos de proteção individual, trouxe a esses trabalhadores à realidade que eles estão expostos diariamente, tornando o conhecimento como principal agente transformador, pois a negação em fazer uso desses acessórios, certamente devia-se ao fato da incompreensão acerca dos mesmos.

\subsection{A coleta de papel nos setores administrativos e acadêmicos da URCA}

Até dezembro de 2017, foram totalizados $2.044 \mathrm{Kg}$ de resíduos sólidos, sendo na sua grande maioria de papéis coletados nos departamentos. Com a análise dos dados da tabela de coleta (Apêndice 1), os setores com maior recolhimento foram a Xerox da URCA, tendo de quatro a cinco coletas semanais, seguido da Pró-Reitoria de Planejamento (PROPLAN) e o Departamento de Ensino e Graduação (DEG) com três a quatro coletas semanais.

Umas das razões pela qual a xerox da universidade ter tanto desperdício, seria a falta de revisão nos documentos antes de serem impressos, bem como, a não utilização da opção "frente e verso", o que faria com que o uso diminuísse consideravelmente. Segundo Santos et al. (2017) os impactos associados a geração de papel não se restringem apenas a sua produção, mas ao desmatamento pelo corte de árvores e poluição do ambiente pela produção industrial.

Quanto ao desperdício na PROPLAN e DEG, se deve pelo fato desses setores receberem uma grande quantidade de solicitações de outros departamentos, sendo que o DEG, atende a todos os cursos da instituição. Outra explicação seria a falta de atenção ao imprimir certos documentos, onde, muitas vezes se encontram folhas desnecessárias para impressão. Souza (2008) citou que se tem verificado que o desperdício de papel nos escritórios pode ser facilmente observado nas salas onde ficam as impressoras, onde, muitas vezes se veem cópias minimamente defeituosas ou folhas apenas com o nome do usuário da rede que mandou imprimir seus relatórios ou trabalhos.

Segundo a Associação Mineira de Defesa do Meio Ambiente (AMDA, 2013), na hora de mandar um texto ou arquivo para a impressora, é necessária uma revisão e evitar a impressão errada ou de apenas uma frase em um papel, o que leva ao gasto desnecessário de papel. 
Uma das possíveis soluções para mitigar a grande quantidade de papel desperdiçado nesses departamentos seria a implantação de um sistema de tramite de documentos para todos os setores da instituição. Segundo Brembatti (2012), as empresas que utilizam os sistemas de tramite, ajudam na redução de uso de matérias-primas (como madeira), de energia, água e de produtos químicos utilizados no processo de produção de papel, além da diminuição no gasto de combustível envolvido na logística e nas despesas de entrega.

A empresa americana Xerox Corporation, utiliza de um sistema que automatiza os fluxos de trabalho baseados em papel, permitindo que os usuários possam ler, assinar, anotar e guardar documentos sem necessidade de imprimir. Segundo Mike Feldman, o diretor da empresa "Imprimir menos não é apenas uma questão de usar menos papel. É trabalhar de forma mais inteligente, melhorando a produtividade, aumentando a velocidade de ligação entre setores e utilizando dados para alavancar negócios" (Ribeiro, 2014).

\subsection{O uso da informação por meio da colagem de adesivos como forma mitigatória no consumo de água e energia}

A campanha de redução de água e energia na universidade, expandiu, de forma significativa, o acesso à informação quanto ao consumo e desperdício na universidade, esclarecendo e conscientizando a comunidade acadêmica. Ainda que a campanha não tenha resultados concretos quanto à diminuição, devido ao pouco tempo em execução, é relevante afirmar que a mobilização trouxe uma nova visão, aos acadêmicos, sobre o modo pelo qual o desperdício de água e energia influencia diretamente no meio ambiente, pois já é notável, na instituição, a redução de ambientes com ventiladores e luzes ligados em salas vazias, bem como, informes sobre vazamentos em encanamentos, o que não era observado antes da campanha.

Segundo Edington (2009), a informação é um elemento fundamental para se alcançar a sustentabilidade. Assim, vale ressaltar que a campanha por meio da informação, está colaborando para a mudança de hábitos da comunidade acadêmica.

\subsection{Campanha de coleta para reutilização de óleo de cozinha, redução de impactos ambientais e causa social}

Até o presente momento, já foram coletados aproximadamente 300 litros de óleo de cozinha usados, sendo estes destinados à empresa Sabão Juá para a fabricação de sabão.

A campanha, teve o princípio de reduzir o impacto gerado pelo descarte incorreto do óleo, uma vez que, traz consequências drásticas ao meio ambiente. Segundo Pinho \& Santos (2017), o descarte de óleo e ácidos graxos em corpos d'água ocasionam a eutrofização do ambiente aquático, pelo consumo de oxigênio por micro-organismos presentes no meio.

Segundo Costa, Lopes e Lopes (2015), grande quantidade de restos de óleo vegetal usado em frituras são despejados nas pias de cozinha, nas águas de riachos e rios, gerando a contaminação da fauna aquática, do solo e a impermeabilidade do mesmo, além de provocar a danificação das tubulações domésticas e das redes de tratamento de esgoto.

Para Lopes e Baldin (2009), o óleo de cozinha quando é jogado diretamente na pia pode causar sérios prejuízos ao meio ambiente e se o produto for descartado nas redes de esgoto poderá encarecer o tratamento dos resíduos em até $45 \%$, o que permanece nos rios poderá provocar a impermeabilização dos leitos e do solo, contribuindo para que ocorram as enchentes.

Portanto, podemos ressaltar o grande impacto minimizador da iniciativa que traz a campanha de reutilização do óleo. Repercussão esta, que não é só de caráter ambiental, mas também social, uma vez que, parte da renda obtida da fabricação do sabão é revertida ao Instituto de Apoio a Crianças com Câncer (IACC).

\subsection{Palestras nas escolas como forma de sensibilização dos estudantes para o futuro}

As palestras realizadas nas referidas escolas, mobilizaram e sensibilizaram cerca de 100 alunos do ensino fundamental e médio do município de Crato-CE, no que se refere à questão ambiental atual, bem como, os assuntos sociais envolvidos nessa problemática. 
A problemática ambiental assume papel de relevância social, cultural, econômica, ecológica, entre outras, em proporções cada vez mais alarmantes e desfavoráveis à qualidade de vida de uma população. Assim, surgem os debates, conscientização, reflexão, mobilizações, para intervir, de forma participativa e comprometida em defesa do ambiente natural e do meio social, bem como, e principalmente, da relação do homem com a natureza.

De acordo com Effting (2007), é evidente a importância de sensibilizar os humanos para que ajam de modo responsável e com consciência, conservando o ambiente saudável no presente e para o futuro; para que saibam exigir e respeitar os direitos próprios e os de toda a comunidade, tanto local como internacional; e se modifiquem tanto interiormente, como pessoas, quanto nas suas relações com o ambiente.

É necessário propor e promover uma Educação Ambiental crítica que aponte para as transformações da sociedade em direção aos novos paradigmas de justiça social e qualidade ambiental (Guimarães, 2007). Para Oliveira et al. (2022), o termo “educação ambiental” diz respeito ao princípio de educação, no qual o conhecimento a respeito da sustentabilidade vai englobar o desenvolvimento, crescimento e princípio ético.

Nesta perspectiva, o desenvolvimento das palestras sobre Educação Ambiental, resultou em conscientização e sensibilização da comunidade escolar, gerando assim, possíveis ações viáveis e ambientalmente corretas.

\section{Conclusão}

Após a realização deste trabalho pode-se concluir que é possível articular e planejar ações que envolvam a comunidade acadêmica, inserido a necessidade de transformar o ambiente onde se vive em prol da melhoria da qualidade de vida e dignidade humana.

A comunidade acadêmica em questão, atualmente está mais interessada em questões socioambientais, contribuindo efetivamente com o programa realizado na instituição, pois desenvolveram uma visão mais realista, racionalizada e concreta da relevância desta temática.

Por fim, observou-se o reconhecimento do Programa de Educação Ambiental como uma eficiente estratégia pedagógica para a melhor gestão dos resíduos sólidos e sua relevância na transformação das atitudes e valorização do meio ambiente na instituição. Contudo, ainda se faz necessário um melhor envolvimento da comunidade acadêmica, principalmente os funcionários da limpeza, para uma melhor valorização das práticas do programa.

O desenvolvimento de programas de educação ambiental se mostrou eficiente no controle de resíduos sólidos, sendo necessário a movimentação e produção de oficinais que busquem abranger um publico maior da comunidade. Dessa forma, a sociedade pode compreender seu papel na sustentabilidade, influenciando na tomada de decisões assertivas.

\section{Agradecimentos}

Agradecemos à Universidade Regional do Cariri (URCA).

\section{Referências}

Araújo, M. C. B., COSTA, D., \& Ferreira, M. (2003). Lixo no ambiente marinho. Ciência hoje, 32(191).

Associação Mineira de Defesa do Meio Ambiente - AMDA. (2013). Informações ambientais. Estante virtual. Belo Horizonte. www.amda.org.br/?string=interna-informacoes-ambientais\&cod=16.

Almeida, S. B. O., Souza, L. D., \& Caldeira, V. P. S. (2021). Preservação e Educação Ambiental na perspectiva de uma comunidade universitária. Revista Brasileira de Educação Ambiental, 16(6), 199-215. doi: 10.34024/revbea.2021.v16.12305

Almeida, I. F. P., \& Silva, J. G. F. (2021). Sustentabilidade na gestão de resíduos sólidos: um estudo de caso em Pinheiros (ES). Revista Brasileira de Educação Ambiental, 16(6), 397-413. doi: 10.34024/revbea.2021.v16.10926 
Research, Society and Development, v. 11, n. 3, e4611325575, 2022

(CC BY 4.0) | ISSN 2525-3409 | DOI: http://dx.doi.org/10.33448/rsd-v11i3.25575

Barreto, A. D. A. (1994). A questão da informação. São Paulo em perspectiva, 8(4), 3-8.

Brembatti, K. (2012). Empresas reduzem o uso de papel. Curitiba. http.://www.gazetadopovo.com.br/vida-e-cidadania/empresas-reduzem-uso-de-papel2ja451sftxqmb9ntm8suo18we.

Cisz, C. R. (2015). Conscientização do uso de EPI'S, quanto à segurança pessoal e coletiva (Trabalho de Conclusão de Curso - Especialização em Engenharia de Segurança do Trabalho). Faculdade de Construção Civil, Universidade Tecnológica Federal do Paraná, PR, Curitiba.

Costa, D. A., Lopes, G. R., \& Lopes, J. R. (2015). Reutilização do óleo de fritura como uma alternativa de amenizar a poluição do solo. Revista Monografias Ambientais, 14, 243-253.

Edington, I. (2009). Importância da informação para o ecodesenvolvimento. http://www.ecodesenvolvimento.org/colunas/isaac-edington/importancia-dainformacao-para-o.

Effting, T. R. (2007). Educação Ambiental nas Escolas Públicas: realidade e desafios (Trabalho de conclusão de curso - Especialização em Planejamento Para o Desenvolvimento Sustentável). Centro de Ciências Agrárias, Universidade Estadual do Oeste, PR, Curitiba.

Felix, R. A. Z. (2007). Coleta seletiva em ambiente escolar. REMEA-Revista Eletrônica do Mestrado em Educação Ambiental, $18,56-71$.

Guimarães, M. (2007). Educação ambiental: no consenso um embate?.São Paulo: Papirus Editora.

Lopes, R. C. \& Baldin, N. (2009). Educação Ambiental para a reutilização do óleo de cozinha na produção de sabão - projeto "Ecolimpo". Anais do IX Congresso Nacional de Educação (EDUCERE) - III Encontro Sul Brasileiro de Psicopedagogia, Paraná, PR, Brasil, 14, $243-253$.

Mucelin, C. A., \& Bellini, M. (2008). Lixo e impactos ambientais perceptíveis no ecossistema urbano. Sociedade \& natureza, 20, 111-124.

Oliveira, B. A., Oliveira, J. C. A., Sobral, S. D. C., Feitosa, T. K. M., Oliveira, E. L., Bento, E. B., Souza, D. L., Alcântara, B. M., Alexandre, C. E. A., Fernandes, P. A. S., Lima, T. F., Gonçalo, M. A. B. F., Oliveira, M. G. (2022). Educação ambiental no Geopark Araripe: contribuição para o ensino de geografia. Research, Society and Development, 11(1), e55711124720. doi: 10.33448/rsd-v11i1.24720

Pereira, F. E.; Oliveira, S. C. G. \& Vieira, V. G. (2013). Educação Ambiental e sustentabilidade. Anais do III Congresso Nacional de Educação Ambiental $U F P B$, Campina Grande, PB, Brasil, 2, 2013.

Pinho, M. J. P., \& Santos, J. L. (2017). Reciclagem de óleos residuais de estabelecimentos gastronômicos na cidade de Jaguarari (BA) por meio da Educação Ambiental. Revista Brasileira de Educação Ambiental, 12(2), 101-113. doi: 10.34024/revbea.2017.v12.2276

Ribeiro, B. (2014). Novas soluções xerox visam mitigar o desperdício de papel. http://www.bitmag.com.br/2014/11/novas-solucoes-xerox-visam-mitigardesperdicio-de-papel/?inf_by=5a2eb35a671db8c4278b4a1d.

Silva, E. A., Oliveira, C. A. M., Cunha, R. R. C. A., Soares, R. V. S., Teixeira, V. D., Guenther, M. (2014). Educação Ambiental voltada para a reutilização e reciclagem dos resíduos sólidos no ambiente escolar: um estudo de caso no ensino fundamental em Recife (PE). Revista Brasileira de Educação Ambiental, $9(2)$, 412-423. doi: 10.34024/revbea.2014.v9.1850

Santos, C. R., Santana, T. C., Azevedo, R. B. R., Pinheiro, P. S. L., Silva, S. N. (2017). Reciclagem de papel e o desenvolvimento de ações sustentáveis: uma parceria entre o PIBID interdisciplinar em Educação Ambiental e a Com-Vida escolar. Revista Brasileira de Educação Ambiental, 12(2), 114-126. doi: 10.34024/revbea.2017.v12.2297

Zitzke, V. A. (2002). Educação Ambiental e Ecodesenvolvimento. Revista Eletrônica do Mestrado em Educação Ambiental, 9, 1-13. 